\title{
Determination of Reductones, Furans and Organic Acids in Aqueous Model Matrices Using Solid-Phase Extraction and Gas Chromatography/Mass Spectrometry
}

\author{
Masataka MORI and Kenji ITO \\ Tobacco Science Research Center, Japan Tobacco Inc., 6-2 Umegaoka, Aoba-ku, Yokohama, Kanagawa 227-8512, Japan
}

Received June 24, 2003; Accepted October 20, 2003

\begin{abstract}
A method using solid-phase extraction (SPE) and GC-MS was developed for the determination of a series of polar and unstable flavor compounds: reductones, furans and volatile organic acids, in aqueous model matrices. The SPE procedures were optimized mainly on the pH-dependency of the analytes with regard to their adsorption characteristics. Good recovery of the reductones except DDMP was obtained at pH 2 and 4.5. Furan derivatives were generally recovered in high yields under the acidic to neutral $\mathrm{pH}$ conditions examined. All organic acids were recovered almost quantitatively at pH 2. An essentially comparable result was obtained in a model Maillard reaction mixture. In order to apply this method to alcoholic beverages, effect of the ethanol concentration on the SPE adsorption of the analytes was also investigated.
\end{abstract}

Keywords: solid-phase extraction (SPE), gas chromatography/mass spectrometry (GC-MS), reductone, furan, organic acid

Reductones, furans (Ledl \& Schleicher, 1990) and organic acids (Hofmann et al., 2000) are commonly found in foods and beverages. Most reductones and volatile acids exhibit important sensory properties with low threshold values, and some of them are utilized as food flavors. Furan derivatives generated from sugars by non-enzymatic browning are closely related to the chemical changes in foods and beverages during their processing and storage (Lee \& Nagy, 1990).

Such types of compounds have relatively high polarity and ionic characters, so that their high water solubility results in low recovery in conventional solvent-extraction methods. Headspace sampling and solid-phase microextraction (SPME) are frequently used for the selective extraction of volatile flavors from a complex matrix. Unfortunately, the main disadvantage of these methods is low recovery of polar analytes (Pan et al., 1995).

In addition, reductones and furans tend to be decomposed during the analytical procedures, particularly at the elevated temperature used in GC analysis (Blank et al., 1992). To compensate for losses during the workup procedure for GC analysis, stable isotope dilution assays (Sen et al., 1991) were developed. However, this technique requires the corresponding isotope-labeled derivative of each analyte as the internal standard.

Column adsorption (Shimoda et al., 1987) and solid phase extraction (SPE) (Coulibaly \& Jeon, 1996) are now widely used for the extraction and clean up of flavor compounds in foods and beverages. Even though some efficient methods had been developed for the analysis of reductones, most of them were optimized to one or a few analytes on high performance liquid chromatography (HPLC) (Walsh et al., 1997). The HPLC methods are not suitable to trace level multiple analytes.

To our knowledge, there were only a few reports concerning the GC-quantitation of such polar and unstable volatiles from aqueous matrices using SPE treatments (Wada \& Shibamoto,

E-mail: masataka.mori@ims.jti.co.jp
1997; Adahchour et al., 1999). Recently, Thum and Back (1999) applied their SPE procedure for a selective concentration of a series of aroma compounds from beer samples. But they had not examined the SPE efficiency for each analyte and the best quantitative results were obtained by the use of different selected internal standards.

In this report, we demonstrate an improvement in the SPE treatments for the GC-quantitation of a wide range of reductones, furans and organic acids in aqueous model matrices. In order to apply this method to alcoholic beverages, the effect of ethanol concentration on SPE adsorption of the analytes was also examined.

\section{Materials and Methods}

Reagents and standard compounds Diethyl ether, acetonitrile and methanol were ultra pure grade (Wako Pure Chemicals Industries). Ether was stabilized by the addition of $0.01 \%$ antioxidant BHT. Distilled deionized water was purified by the Milli$\mathrm{Q}^{\circledR}$ system (Millipore) and used in all procedures.

The following substances were purchased from Sigma-Aldrich Chemical Company with purity of at least 97\%: 3-hydroxy2-methyl-4H-pyran-4-one (maltol), 2,5-dimethyl-4-hydroxy$3(2 \mathrm{H})$-furanone (furaneol), 3-methyl-1,2-cyclopentanedione (cyclotene), 2-furfural (furfural), 2-furanmethanol (furanmethanol), 2-furancarboxylic (furoic) acid, 5-methyl-2-furfural, 5-hydroxymethyl-2-furfural (5-HMF), butyric acid, isobutyric acid, 3-methylbutanoic (isovaleric) acid, pentanoic (valeric) acid, hexanoic acid and L-proline. D-Maltose monohydrate and butyrated hydroxytoluene (BHT) were the products of Wako Pure Chemicals Industries. Hexanoic acid-d $\mathrm{d}_{11}(98 \%$ D) was supplied by Cambridge Isotope Laboratory Inc. p-Bromophenethyl alcohol (98\% purity) was a product of Sigma-Aldrich Chemical Company.

The sample of 2,3-dihydro-3,5-dihydroxy-6-methyl-4H-pyran-4-one (DDMP) was chromatographically separated from vacuum pyrolysate at $150-160^{\circ} \mathrm{C} / 133.3 \mathrm{~Pa}$ of 1 -deoxy-1-prolino- 
Table 1. Contents of standard stock solutions of furans, organic acids and selected analytes.

\begin{tabular}{|c|c|c|c|c|c|}
\hline \multicolumn{2}{|c|}{ STD1 (Furans) } & \multicolumn{2}{|c|}{ STD2 (Organic acids) } & \multicolumn{2}{|c|}{ STD3 (Selected analytes) } \\
\hline & $(\mu \mathrm{g} / \mathrm{ml})$ & & $(\mu \mathrm{g} / \mathrm{ml})$ & & $(\mu \mathrm{g} / \mathrm{ml})$ \\
\hline Furfural & 1310 & Butyric acid & 890 & Cyclotene & 1060 \\
\hline Furanmethanol & 550 & Isobutyric acid & 860 & Maltol & 5030 \\
\hline 5-Methylfurfural & 710 & Valeric acid & 970 & Furaneol & 5070 \\
\hline Acetylfuran & 990 & Isovaleric acid & 810 & DDMP & 1050 \\
\hline 5-HMF & 2030 & Hexanoic acid & 860 & Furoic acid & 10400 \\
\hline \multirow[t]{3}{*}{ BHT } & 520 & BHT & 840 & 2-HAF & 1170 \\
\hline & & & & Benzoic acid & 4430 \\
\hline & & & & BHT & 400 \\
\hline
\end{tabular}

BHT: butyrated hydroxytoluene.

D-fructose according to the method of Mills et al. (1970) and purified by recrystallization, m.p. $73.0-73.6^{\circ} \mathrm{C}$; Lit.: $73-74^{\circ} \mathrm{C}$ (Kim \& Baltes, 1996). Crystalline 2-hydroxyacetylfuran (2HAF), m.p. $82.5-83.2^{\circ} \mathrm{C}$; Lit.: $83-84.5^{\circ} \mathrm{C}$ (Miller \& Cantor, 1952), was synthesized from 2-acetylfuran by the procedure described by Moriarty et al. (1992).

Standard solutions Three kinds of standard solutions (STD1-3) were prepared in acetonitrile separately (Table 1). BHT was added to prevent oxidative degradation of the analytes. The standards were stocked at $5^{\circ} \mathrm{C}$ in a refrigerator until use. The addition of less than $1 \%$ of acetonitrile in aqueous sample solution did not essentially affect the recovery of the SPE procedure except for highly polar DDMP (data not shown). The internal standards (I.S.) were hexanoic acid- $\mathrm{d}_{11}(12.50 \mathrm{mg} / 10 \mathrm{ml})$ and $p$ bromophenethyl alcohol $(12.36 \mathrm{mg} / 10 \mathrm{ml})$ in acetonitrile.

Sugar-amino acid model reaction Maltose monohydrate ( $36 \mathrm{~g}, 0.1 \mathrm{~mole}$ ) and proline ( $34.5 \mathrm{~g}, 0.3 \mathrm{~mole}$ ) were dissolved in $100 \mathrm{ml}$ of $0.2 \mathrm{M}$ phosphate buffer $(\mathrm{pH} 6.5)$. The mixture $(\mathrm{pH}$ 6.44) was degassed with a water-aspirator under sonic agitation and heated under an argon atmosphere at $100 \pm 2^{\circ} \mathrm{C}$ for $8 \mathrm{~h}$ with magnetic stirring. The resulting reaction mixture was cooled in an ice-water bath and stored at $5^{\circ} \mathrm{C}$ in a refrigerator.

For the determination of the analytes and the recovery studies, a solution containing either $0.2,2$ or $5 \mathrm{ml}$ of this reaction mixture in $25 \mathrm{ml}$ of water was spiked with $50 \mu \mathrm{l}$ of a standard solution and applied for the SPE treatment.

Solid-phase extraction (SPE)

Pre-washing/conditioning An OASIS ${ }^{\circledast}$ HLB $0.5 \mathrm{~g} / 6 \mathrm{cc}$ LP cartridge (divinylbenzene- $N$-vinyl-pyrrolidine copolymer, Waters) (Peruzzi et al., 2000) was washed successively with $5 \mathrm{ml}$ of diethyl ether and methanol. Finally, the cartridge was conditioned with $10 \mathrm{ml}$ of water (or aqueous $0.01 \mathrm{M} \mathrm{HCl}$ for the treatment at $\mathrm{pH} 2$ ).

PH adjustment of sample solution A sample $(0.2-5 \mathrm{ml})$ solution and internal standard $(50 \mu \mathrm{l})$ were placed in a $50 \mathrm{ml}$ glass vial and diluted to $25 \mathrm{ml}$ with water. The $\mathrm{pH}$ of the mixture was adjusted to the indicated value with $0.1-0.01 \mathrm{M} \mathrm{HCl}$ or $0.1-$ $0.01 \mathrm{M} \mathrm{NaOH}$ solutions under vigorous stirring. The established $\mathrm{pH}$ conditions were (A) $\mathrm{pH} 4.5$ for reductones and furans (I.S.: $p$-bromophenethyl alcohol) and (B) $\mathrm{pH} 2$ for organic acids (I.S.: hexanoic acid- $\mathrm{d}_{11}$ ), respectively. Then, a $20 \mathrm{ml}$ portion of the sample solution was loaded onto the OASIS cartridge.

Washing and drying The cartridge was washed with $10 \mathrm{ml}$ of water (or aqueous $0.01 \mathrm{M} \mathrm{HCl}$ for organic acids) and flushed with a nitrogen stream at $2 \mathrm{~atm}$. The nitrogen flush was continued until no water was drained.
Extraction The cartridge was eluted with $10 \mathrm{ml}$ of diethyl ether. Since a small volume of the residual water was often coeluted, the eluate was vigorously shaken with sodium sulfate ( 2.5 g) and the organic layer was again dried over anhydrous sodium sulfate. Three micro liters of this solution was injected for GCMS analysis without concentration.

GC-MS analysis An Agilent 6890 gas chromatograph/ 5973N mass selective detector equipped with a CTC Analytics CombiPAL autosampler was used for the qualitative and quantitative analysis under the following conditions. Column: HPFFAP (polypropylene glycol-acid modified, J\&W Scientific) $30 \mathrm{~m} \times 0.25 \mathrm{~mm}, 0.25 \mu \mathrm{m}$ film thickness, carrier gas: helium at $42 \mathrm{~cm} / \mathrm{s}$, inlet temperature: $200^{\circ} \mathrm{C}$, MSD interface temperature: $250^{\circ} \mathrm{C}$, pulsed-splitless injection. The oven temperature was programmed from $60^{\circ} \mathrm{C}$ ( 2 min hold) to $240^{\circ} \mathrm{C}(15 \mathrm{~min}$ hold $)$ at a rate of $5^{\circ} \mathrm{C} / \mathrm{min}$. For the GC-quantitation in split injection mode (split ratio $10: 1$ ), carrier gas: helium at $40 \mathrm{~cm} / \mathrm{s}$; inlet temperature: $230^{\circ} \mathrm{C}$. The temperature program consisted of $60^{\circ} \mathrm{C}(2 \mathrm{~min}$ hold) to $120^{\circ} \mathrm{C}$ at a rate of $10^{\circ} \mathrm{C} / \mathrm{min}$, increased to $180^{\circ} \mathrm{C}$ at a rate of $3^{\circ} \mathrm{C} / \mathrm{min}$, followed by increased to a final temperature of $240^{\circ} \mathrm{C}(15 \mathrm{~min}$ hold $)$ at a rate of $10^{\circ} \mathrm{C} / \mathrm{min}$. MS-library searching was performed on the Wiley 275 database.

\section{Results and Discussion}

$G C-M S$ quantitation Because of the diversity of thermal stability among the target analytes, two different GC conditions were employed for their quantitation. The GC parameters are listed in Table 2.

The analyses on most of the furans and organic acids were performed on the basis of the target ion in scanning (SCAN) mode. By using the pulsed-splitless injection mode to suppress the peak broadenings of the furans and organic acids, good linearity was obtained. Hexanoic acid- $\mathrm{d}_{11}$ was selected as the internal standard for organic acids, because of the better GC-separation from the unlabeled specimen than that of pentanoic acid$\mathrm{d}_{9}$.

On the other hand, remarkable decreases of the $\mathrm{GC}$ responses in reductones and some furans in their lower ranges were observed, probably due to their thermal degradation on their GCanalysis (Blank et al., 1992). To reduce the sample degradation on the GC-injection step, the split mode was employed for the unstable reductones and furans. The resulting decline in the GCresponses of these analytes could be compensated by use of the selective ion-monitoring (SIM) mode. For the more precise quantitation of these analytes, different calibration curves were needed in their lower ranges. 
PH dependency on the recovery of the analytes Considering the various factors affecting the recovery of the analytes in SPE procedures, we focused on the $\mathrm{pH}$ dependency of the polarity of acidic compounds (Albertsson et al., 1995), such as organic acids and reductones, with regard to their breakthrough and adsorption characteristics.

To estimate the participation of the $\mathrm{pH}$ dependency, the conditions of $\mathrm{pH} \mathrm{2,} 4.5$ and 7 for the SPE treatments were examined. As can be seen in Table 3, high recovery of reductones was obtained under acidic (pH 2 and 4.5) conditions. This result coincided with the fact that the stability of unstable furaneol (Hirvi et al., 1980) in aqueous solution is maximal at $\mathrm{pH} 3.5$. The weakly acidic nature of reductones may cause their lower recovery at $\mathrm{pH}$ 7. The low value of DDMP (Mills et al., 1970), which is known to be unstable and highly polar, was an exceptional case. In contrast to other reductones, the recovery of DDMP under acidic conditions was lower than that at neutral $\mathrm{pH}$. Whereas furanmethanol and 5-HMF had been reported to be unstable under acidic conditions (Birkofer \& Beckmann, 1959), over 92\% recovery for the furan derivatives except 2-HAF was obtained under the acidic to neutral conditions examined in this experiment. Most of the organic acids were recovered almost quantitatively at $\mathrm{pH} 2$. The peak broadening of furoic acid on the GC analysis caused somewhat lower recovery $(90.3 \%)$ and reproducibility.

Since the recovery of DDMP at $\mathrm{pH} 4.5$ was higher than that at $\mathrm{pH} 2$, this condition was selected for the simultaneous determinations of reductones and furans, and $\mathrm{pH} 2$ for the analysis of

Table 2. GC-quantitation parameters of furans and organic acids, and the selected analytes.

\begin{tabular}{|c|c|c|c|c|c|}
\hline Target compound & GC mode ma $^{a}$ & Retention time (min) & 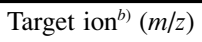 & Calibration range (ppm) & Coefficient of determination $\left(r^{2}\right)$ \\
\hline Furfural & a & 10.82 & 96 & $0.3-30$ & 1.000 \\
\hline Furanmethanol & $\mathrm{a}$ & 15.37 & 98 & $0.2-20$ & 1.000 \\
\hline 5-Methylfurfural & a & 13.41 & 110 & $0.1-10$ & 1.000 \\
\hline Acetylfuran & a & 11.77 & 95 & $0.1-10$ & 1.000 \\
\hline 5-HMF & a & 31.45 & 97 & $0.4-40$ & 1.000 \\
\hline Isobutyric acid & a & 13.23 & 73 & $0.2-20$ & 1.000 \\
\hline Butyric acid & a & 14.63 & 60 & $0.2-20$ & 1.000 \\
\hline Isovaleric acid & a & 15.57 & 60 & $0.2-20$ & 1.000 \\
\hline Valeric acid & $\mathrm{a}$ & 17.09 & 60 & $0.2-20$ & 1.000 \\
\hline Hexanoic acid & $\mathrm{a}$ & 19.40 & 60 & $0.2-20$ & 1.000 \\
\hline Cyclotene & $\mathrm{b}$ & 15.07 & $112(69)$ & $0.4-20$ & 1.000 \\
\hline \multirow[t]{2}{*}{ Maltol } & $\mathrm{b}$ & 18.99 & 71 (126) & $10-100$ & 0.999 \\
\hline & & & & $2-10$ & 0.981 \\
\hline \multirow[t]{2}{*}{ Furaneol } & $\mathrm{b}$ & 20.32 & $128(57)$ & $5-100$ & 1.000 \\
\hline & & & & $2-10$ & 0.995 \\
\hline DDMP & $\mathrm{b}$ & 26.75 & $144(101)$ & $10-100$ & 0.998 \\
\hline \multirow[t]{2}{*}{ 2-HAF } & $\mathrm{b}$ & 19.59 & $95(126)$ & $1-20$ & 1.000 \\
\hline & & & & $0.5-2$ & 0.981 \\
\hline \multirow[t]{2}{*}{ Furoic acid } & $\mathrm{b}$ & 31.10 & $112(95)$ & $20-200$ & 0.998 \\
\hline & & & & $4-20$ & 0.966 \\
\hline \multirow[t]{2}{*}{ Benzoic acid } & $\mathrm{b}$ & 30.55 & $105(122)$ & $0.4-20$ & 0.999 \\
\hline & & & & $0.4-4$ & 0.995 \\
\hline
\end{tabular}

a) GC mode: a: pulsed-splitless/SCAN, b: split/SIM.

${ }^{b)}$ Qualifier ion in SIM mode are shown in parentheses.

Analyses were performed in triplicate.

Table 3. Effects of $\mathrm{pH}$ on recoveries of the analytes from water matrices.

\begin{tabular}{|c|c|c|c|c|c|c|c|}
\hline & \multirow{2}{*}{ GC mode ${ }^{a)}$} & \multicolumn{2}{|c|}{$\mathrm{pH} 2^{b)}$} & \multicolumn{2}{|c|}{$\mathrm{pH} 4.5$} & \multicolumn{2}{|c|}{$\mathrm{pH} 7$} \\
\hline & & Recovery $^{c)}$ & RSD & Recovery & RSD & Recovery & RSD \\
\hline Cyclotene & $\mathrm{b}$ & 104 & 1 & 98.1 & 0.5 & 90.3 & 0.3 \\
\hline Maltol & $\mathrm{b}$ & 103 & 2 & 99.5 & 2.1 & 84.8 & 0.8 \\
\hline Furaneol & $\mathrm{b}$ & 92.3 & 1.2 & 90.2 & 0.6 & 69.8 & 0.2 \\
\hline DDMP & $\mathrm{b}$ & 34.7 & 17.3 & 45.9 & 2.0 & 47.3 & 1.2 \\
\hline 2-Furfural & $\mathrm{a}$ & 106 & 4 & 94.7 & 0.5 & 97.9 & 2.9 \\
\hline 2-Acetylfuran & $\mathrm{a}$ & 106 & 4 & 94.6 & 0.9 & 98.8 & 2.6 \\
\hline 5-Methylfurfural & $\mathrm{a}$ & 105 & 4 & 94.2 & 0.8 & 97.7 & 2.9 \\
\hline Furanmethanol & $\mathrm{a}$ & 102 & 5 & 92.2 & 1.3 & 96.3 & 4.7 \\
\hline 5-HMF & $\mathrm{a}$ & 103 & 3 & 97.1 & 2.8 & 97.2 & 1.0 \\
\hline 2-HAF & $\mathrm{b}$ & 83.6 & 11.0 & 78.7 & 5.1 & 69.6 & 1.1 \\
\hline Isobutyric acid & $\mathrm{a}$ & 101 & 2 & 89.7 & 0.8 & 0.0 & - \\
\hline Butanoic acid & $\mathrm{a}$ & 105 & 0 & 91.0 & 1.8 & 0.0 & - \\
\hline Isovaleric acid & $\mathrm{a}$ & 101 & 1 & 97.8 & 0.8 & 0.2 & - \\
\hline Valeric acid & $\mathrm{a}$ & 105 & 0 & 102 & 1 & 0.6 & - \\
\hline Hexanoic acid & $\mathrm{a}$ & 106 & 1 & 102 & 1 & 26.8 & 17.5 \\
\hline Furoic acid & $\mathrm{b}$ & 90.3 & 4.9 & 67.9 & 2.8 & 34.2 & 0.1 \\
\hline Benzoic acid & $\mathrm{b}$ & 97.8 & 3.2 & 85.1 & 1.2 & 20.7 & 17.5 \\
\hline
\end{tabular}

a) GC mode: a: pulsed-splitless/SCAN, b: split/SIM

${ }^{b)} \mathrm{pH}$ of sample solution.

${ }^{c)}$ Recovery values and relative standard deviations are expressed in percentages. 
Table 4. Concentration of the analytes in the model matrix and recoveries of spiked standards.

\begin{tabular}{lccccc}
\hline & \multicolumn{2}{c}{ Mean value $^{a)}$} & & \multicolumn{2}{c}{ Recovery studies $^{c)}$} \\
\cline { 2 - 3 } & $\mathrm{ppm}(\mu \mathrm{g} / \mathrm{ml})$ & $\mathrm{SD}$ & & Recovery(\%) & $\mathrm{RSD}$ \\
\hline Cyclotene & 8.60 & 0.14 & $\mathrm{~b}$ & 97.7 & 0.4 \\
Maltol & 1360 & 40 & $\mathrm{a}$ & 104 & 1 \\
Furaneol & 29.7 & 0.1 & $\mathrm{~b}$ & 79.0 & 0.4 \\
DDMP & 533 & 2 & $\mathrm{a}$ & 14.2 & 0.6 \\
2-Furfural & 1.18 & 0.06 & $\mathrm{c}$ & 81.1 & 4.0 \\
2-Acetylfuran & 15.1 & 0.5 & $\mathrm{a}$ & 101 & 5 \\
Furanmethanol & 586 & 23 & $\mathrm{a}$ & 90.3 & 5.4 \\
5-HMF & 8.28 & 0.17 & $\mathrm{~b}$ & 84.8 & 0.1 \\
2-HAF & 12.7 & 0.3 & $\mathrm{~b}$ & 80.9 & 1.7 \\
Furoic acid & 22.8 & 2.9 & $\mathrm{~b}$ & 97.4 & 9.1 \\
\hline
\end{tabular}

SD: standard deviation; RSD: relative standard deviation.

${ }^{a)}$ Mean value in triplicate sample preparations.

b) Quantity of added model reaction mixture in $25 \mathrm{ml}$ of sample solution. (see Materials and Methods) a: $0.2 \mathrm{ml}$, b: $2 \mathrm{ml}$, c: $5 \mathrm{ml}$.

c) $50 \mu \mathrm{l}$ of the standard solutions were spiked to the sample which contained the indicated levels of the model matrix.

organic acids including furoic acid.

Application to a model reaction mixture This method was applied to a model Maillard reaction mixture to evaluate its availability. For the model matrix, we selected the heated aqueous solution of maltose-proline, in which maltol and furanmethanol were contained as the major products (Yaylayan \& Mandeville, 1994). Relatively small amounts and trace levels of the other three reductones and five furans could also be detected. Since the concentration of the products varied markedly, the appropriate dilution within the calibration range was needed for the determination of each analyte. The quantitative results for the model mixture and the recovery of the spiked standards using the estimated standard curves are also given in Table 4. The yield of DDMP was considerably diminished and those of furaneol, 2furfural and 5-HMF were somewhat decreased. The recovery of most analytes, however, was shown to be over $80 \%$ and essentially comparable with that from the water matrix.

Effects of ethanol on the SPE adsorption of the analytes In recent years, several SPE procedures including column adsorption techniques to extract aroma compounds from alcoholic beverages have been reported (Ferreira et al., 2000). However, these methods are usually limited to the analysis of relatively low polar components. In order to apply the method described in this study to alcoholic beverages, the effect of ethanol concentration on the SPE adsorption of the highly polar analytes was estimated.

Sample solutions containing 0.5, 1, 2 and 5\% of ethanol were spiked with the standard mixture of the analytes. These were applied to the SPE procedures, and recovery values for the analytes were compared with that of the ethanol-free sample (Fig. $1 \mathrm{a}-\mathrm{c})$.

As can be seen in Fig. 1a, the recoveries of cyclotene, maltol and furaneol were essentially unchanged up to $2 \%$ ethanol concentration, and then decreased to $88.4,85.9$, and $70.4 \%$ at $5 \%$ ethanol levels, respectively. The recovery of DDMP dropped even at $0.5-1 \%$ ethanol levels. On the other hand (Fig. 1b), considerable reductions in the recoveries of furanmethanol, 2-HAF and 5-HMF were observed, whereas those of furfural, acetylfuran and 5-methylfurfural were decreased only slightly at 5\% ethanol levels.

Since the recovery of all reductones and furans except DDMP

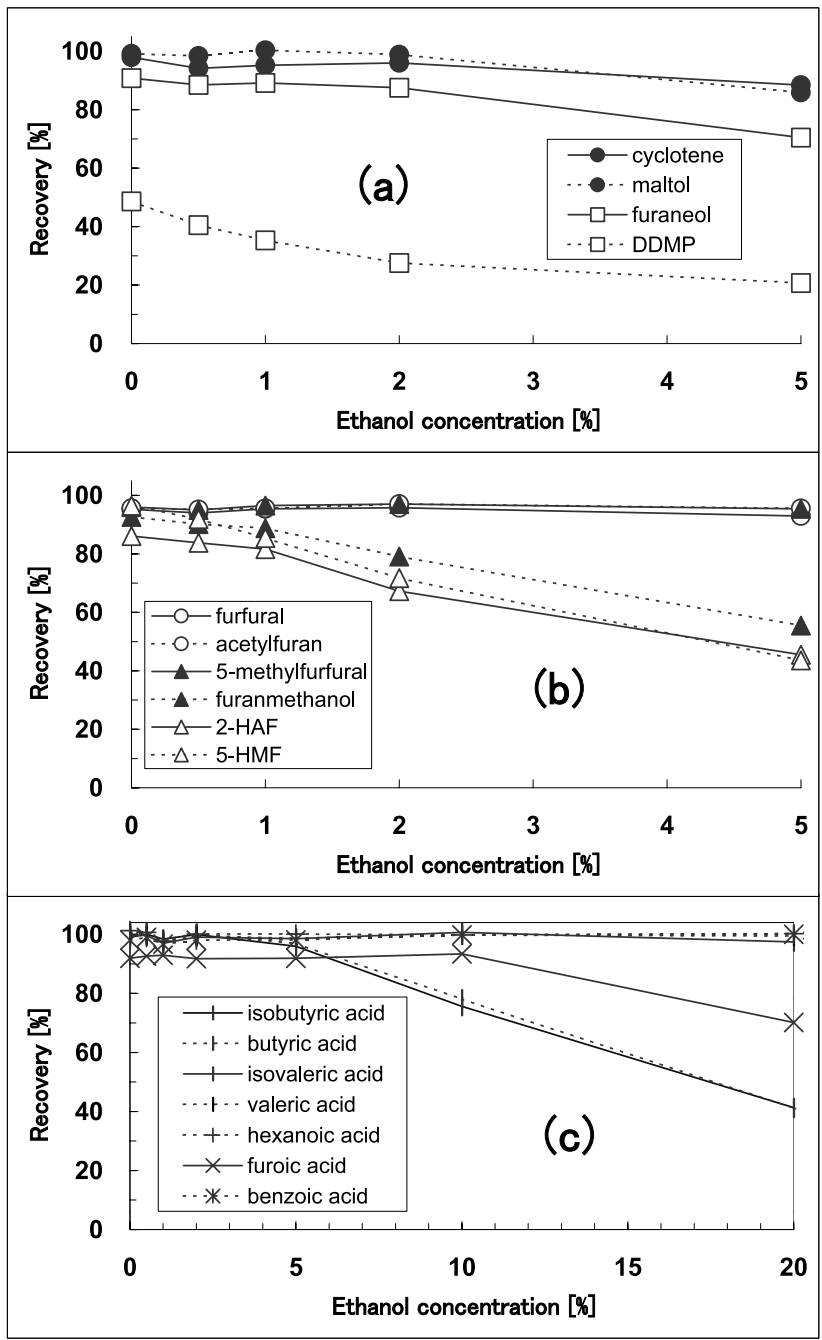

Fig. 1. Effects of ethanol concentration on the recoveries of (a) reductones, (b) furans, and (c) organic acids. The recovery values were the mean of two experiments.

were sufficiently high at $1 \%$ ethanol levels, a dilution to less than $1 \%$ level of ethanol concentration may permit this SPE method to be used in the simultaneous determination of these analytes in alcoholic beverages.

In contrast to the reductones and furans, recovery of the organic acids was almost quantitative up to $5 \%$ of the ethanol concentration. Thus, the recoveries in 10 and $20 \%$ ethanol levels were also estimated. Figure 1c shows that there is essentially no interference of ethanol in the recoveries of isovaleric, valeric, hexanoic or benzoic acids in the $0.5-20 \%$ range of ethanol concentration. However, the recoveries of butyric- and isobutyric acids begin to decline at $5 \%$ ethanol concentration and decrease to 75.6 and $78.1 \%$ at $10 \%$ ethanol concentration, respectively. The recovery of furoic acid was also reduced to $70.1 \%$ at the $20 \%$ ethanol level. The above results showed that the adjustment of ethanol concentration to less than $5 \%$ would be needed for the simultaneous determination of all organic acids examined in this study.

In conclusion, good recovery on the GC-MS quantitation of polar and unstable flavor compounds in aqueous model matrices were achieved by the SPE treatments with $\mathrm{pH}$ regulation. Under 
the two conditions ( $\mathrm{pH} 4.5$ and 2) used in the SPE treatments, most of the sixteen analytes could be recovered almost quantitatively. In addition, the appropriate dilution may permit the application of this method to determine the analytes in alcoholic beverages.

Acknowledgments We thank Ms. Emiko Yasuda of JT Creative Service for her technical assistance.

\section{References}

Adahchour, M., Vreuls, R.J.J., van der Heijden, A. and Brinkman, U.A.Th. (1999). Trace-level determination of polar compounds in butter by solid-phase extraction and gas chromatography-mass spectrometry. J. Chromatogr. A, 844, 295-305.

Albertsson, A.C., Barenstedt, C. and Karlsson, S. (1995). Solid-phase extraction and gas chromatographic-mass spectrometric identification of degradation products from enhanced environmental degradable polyethylene. J. Chromatogr. A, 690, 207-217.

Birkofer, L. and Beckmann, F. (1959). Hydrolyse des Furfurylalkohols. Liebigs Annalen der Chemie, 620, 21-31.

Blank, I., Sen, A. and Grosch, W. (1992). Potent odorant of the roasted powder and brew of arabica coffee. Z. Lebensm. Unters. Forsch, 195, 239-245.

Coulibaly, K. and Jeon, I.J. (1996). An overview of solid-phase extraction of food flavor compounds and chemical residues. Food Rev. Int., 12, 131-151.

Ferreira, V., Ortega, L., Escudero, A. and Cacho, J.F. (2000). A comparative study of the ability of different solvents and adsorbents to extract aroma compounds from alcoholic beverages. J. Chromatogr. Sci., 38, 469-476.

Hirvi, T., Honkanen, E. and Pyysalo, T. (1980). Stability of 2,5-dimethyl-4-hydroxy-3(2H)furanone and 2,5-dimethyl-4-methoxy$3(2 H)$ furanone in aqueous buffer solution. Lebensm. Wiss. Technol., 13, 324-325.

Hofmann, T., Münch, P. and Schieberle, P. (2000). Quantitative model studies on the formation of aroma-active aldehydes and acids by Strecker-type reactions. J. Agric. Food Chem., 48, 434-440.

Kim, M.-O. and Baltes, W. (1996). On the role of 2,3-dihydro-3,5dihydroxy-6-methyl-4H-pyran-4-one in the Maillard reaction. $J$. Agric. Food Chem., 44, 282-289.

Ledl, F. and Schleicher, E. (1990). New aspects of the Maillard reac- tion in foods and in the human body. Angew. Chem. Int. Ed. Engl., 29, 565-594.

Lee, H.S. and Nagy, S. (1990). Relative reactivities of sugars in the formation of 5-hydroxymethylfurfural in sugar-catalyst model systems. J. Food Process. Preserv., 14, 171-178.

Miller, R.E. and Cantor, S.M. (1952). 2-Hydroxyacetylfuran from sugars. J. Am. Chem. Soc., 74, 5236.

Mills, F.D., Weisleder, D. and Hodge, J.E. (1970). 2,3-Dihydro-3,5dihydroxy-6-methyl-4H-pyran-4-one, a novel nonenzymatic browning product. Tetrahedron Lett., 15, 1243-1246.

Moriarty, R.M., Berglund, B.A. and Penmsta, R. (1992). Direct $\alpha$-hydroxylation of ketones under acidic conditions using [bis(trifluoroacetoxy)] iodobenzene. Tetrahedron Lett., 33, 6065-6068.

Pan, L., Adams, M. and Pawliszyn, J. (1995). Determination of fatty acids using solid-phase microextraction. Anal. Chem., 67, 43964403.

Peruzzi, M., Bartolucci, G. and Cioni, F. (2000). Determination of phenoxyalkanoic acids and other herbicides at the $\mathrm{ng} / \mathrm{ml}$ level in water by solid-phase extraction with poly(divinylbenzene-co- $N$ vinylpyrrolidone) sorbent and high-performance liquid chromatography-diode-array detection. J. Chromatogr. A, 867, 169-175.

Sen, A., Schieberle, P. and Grosch, W. (1991). Quantitative determination of 2,5-dimethyl-4-hydroxy-3(2H)-furanone and its methyl ether using a stable isotope dilution assay. Lebensm. Wiss. Technol., 24, 364-369.

Shimoda, M., Hirano, K. and Osajima, Y. (1987). Concentration of volatile components in foods with porous polymer column. Bunseki Kagaku, 36, 792-798 (in Japanese).

Thum, B. and Back, W. (1999). Schonende Analysenmethoden zur Quantifizierung von Schlüsselaromastoffen in Bier. Proceedings of the 27th European Brewery Convention Congress, pp. 45-52.

Wada, K. and Shibamoto, T. (1997). Isolation and identification of volatile compounds from a wine using solid-phase extraction, gas chromatography and gas chromatography/mass spectrometry. J. Agric. Food Chem., 45, 4362-4366.

Walsh, M., Rouseff, R. and Naim, M. (1997). Determination of furaneol and $p$-vinylguaiacol in orange juice employing differential UV wavelength and fluorescence detection with a unified solid-phase extraction. J. Agric. Food Chem., 45, 1320-1324.

Yaylayan, V.A. and Mandeville, S. (1994). Stereochemical control of maltol formation in Maillard reaction. J. Agric. Food Chem., 42, $771-775$. 